\title{
Fleksy: a flexible approach to induced fit docking
}

\author{
Markus Wagener $^{1 *}$, SB Nabuurs ${ }^{2}$, J de Vlieg ${ }^{1}$ \\ From 5th German Conference on Cheminformatics: 23. CIC-Workshop \\ Goslar, Germany. 8-10 November 2009
}

Protein receptor rearrangements upon ligand binding are a major complicating factor in structure-based drug design. An accurate prediction of these so-called induced fit phenomena calls for ligand docking and virtual screening approaches capable of considering receptor flexibility.

We present Fleksy [1], a flexible approach aimed at accurately positioning small molecule ligands into a protein receptor, while taking both ligand and receptor flexibility into account. Our method consists of an ensemble docking stage in which the ligand of interest is docked into a structural ensemble of receptor conformations, followed by a complex optimization stage during which both ligand and protein are allowed to move. Pivotal to our method is the use of receptor ensembles to describe protein flexibility. To construct these ensembles we use a backbone dependent rotamer library and implement the concept of interaction sampling. The latter allows for the evaluation of different orientations and, when relevant, different tautomers of ambivalent interaction partners in the binding site such as asparagine, glutamine and histidine side chains. The docking stage comprises an ensemble-based soft-docking experiment using FlexX-Ensemble [2], followed by an effective flexible receptor-ligand complex optimization using Yasara [3]. Ultimately Fleksy results in a set of receptor-ligand complexes ranked using a consensus scoring function which combines both docking scores and force field energies. Figure 1.

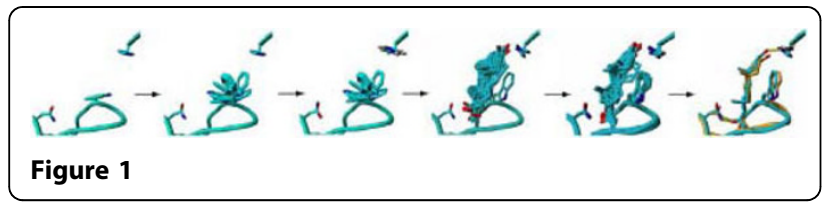

${ }^{1}$ Schering-Plough Research Institute, PO Box 20, 5340BH Oss, The Netherlands
Averaged over three cross-docking datasets, in total containing 35 different pharmaceutically relevant receptor-ligand complexes, Fleksy reproduces the observed binding mode within $2.0 \AA$ for $78 \%$ of the complexes. This compares favorably to the rigid receptor FlexX program [4] which on average reaches a success rate of $44 \%$ for these datasets.

\section{Author details}

${ }^{1}$ Schering-Plough Research Institute, PO Box 20, 5340BH Oss,

The Netherlands. ${ }^{2}$ Nijmegen, The Netherlands.

Published: 4 May 2010

\section{References}

1. Nabuurs SB, Wagener M, de Vlieg J: J Med Chem 2007, 50:6507.

2. Claussen H, Buning C, Rarey M, Lengauer T: J Mol Biol 2001, 308:377.

. [http://www.yasara.org/]

4. Rarey M, Kramer B, Lengauer T, Klebe G: J Mol Biol 1996, 261:470.

doi:10.1186/1758-2946-2-S1-024

Cite this article as: Wagener et al:: Fleksy: a flexible approach to induced fit docking. Journal of Cheminformatics 2010 2(Suppl 1):O24. 